Article

\title{
Evaluation of Lip Morphology and Nasolabial Angle in Non-Syndromic Cleft Lip and/Palate and Non-Cleft Individuals
}

\author{
Mohammad Khursheed Alam ${ }^{1, *}++^{\mathbb{D}}$, Ahmed Ali Alfawzan ${ }^{2,+}{ }^{\text {, Fatema Akhter }}{ }^{3}$, Haytham Jamil Alswairki ${ }^{4}$ \\ and Prabhat Kumar Chaudhari ${ }^{5}$ (D)
}

1 Orthodontics, Preventive Dentistry Department, College of Dentistry, Jouf University, Sakaka 72345, Saudi Arabia

2 Department of Preventive Dentistry, College of Dentistry in Ar Rass, Qassim University, Buraydah 52571, Saudi Arabia; ah.alfawzan@qu.edu.sa

3 Department of Surgical and Diagnostic Sciences, College of Dentistry, Dar Al Uloom University, Riyadh 11512, Saudi Arabia; mstfatima@dau.edu.sa

4 School of Dental Sciences, Universiti Sains Malaysia, Kota Bharu 16150, Malaysia; hitham.swerki@gmail.com

5 Division of Orthodontics and Dentofacial Deformities, Centre for Dental Education and Research, All India Institute of Medical Sciences, New Delhi 110029, India; dr.prabhatkc@gmail.com

* Correspondence: mkalam@ju.edu.sa or dralam@gmail.com

+ These authors contributed equally to this work.

check for updates

Citation: Alam, M.K.; Alfawzan,

A.A.; Akhter, F.; Alswairki, H.J.; Chaudhari, P.K. Evaluation of Lip Morphology and Nasolabial Angle in Non-Syndromic Cleft Lip and/Palate and Non-Cleft Individuals. Appl. Sci. 2022, 12, 357. https://doi.org/ 10.3390/app12010357

Academic Editor: Mitsuru Motoyoshi

Received: 13 November 2021 Accepted: 29 December 2021 Published: 30 December 2021

Publisher's Note: MDPI stays neutral with regard to jurisdictional claims in published maps and institutional affiliations.

Copyright: (C) 2021 by the authors. Licensee MDPI, Basel, Switzerland. This article is an open access article distributed under the terms and conditions of the Creative Commons Attribution (CC BY) license (https:// creativecommons.org/licenses/by/ $4.0 /)$.

\begin{abstract}
Objective: To investigate the variation between the non-syndromic cleft lip and/or palate (NSCLP) and non-cleft (NC) subjects in relation to the lip morphology (LM) and nasolabial angle (NLA). Materials and Methods: Lateral cephalogram (Late. Ceph.) of 123 individuals (92 NSCLP [29 = bilateral cleft lip and palate (BCLP), $41=$ unilateral cleft lip and palate (UCLP), $9=$ unilateral cleft lip and alveolus (UCLA), 13 = unilateral cleft lip (UCL)], and $31 \mathrm{NC}$ ) who did not undergo any orthodontic treatment were investigated. By WebCeph, an artificial intelligence- (A.I.) driven software, 2 (two) parameters of LM, namely upper lip to E line (LM-1) and lower lip to E line (LM-2), and NLA analysis was carried out for each individual. Multiple tests were carried out for statistical analysis. Results: The mean \pm SD observed for LM-1, LM-2, and NLA for NC individuals were $1.56 \pm 2.98,0.49 \pm 3.51$, and $97.20 \pm 16.10$, respectively. On the other hand, the mean $\pm \mathrm{SD}$ of LM-1, LM-2, and NLA for NSCLP individuals were $4.55 \pm 4.23,1.68 \pm 2.82$, and $82.02 \pm 14.66$, respectively. No significant variation was observed with respect to gender and side. NSCLP (different types) and NC individuals showed significant disparities in LM-1 and NLA. Conclusion: It can be concluded that parameters of lip morphology such as LM-1, LM-2, and NLA vary among NSCLP and NC individuals.
\end{abstract}

Keywords: non-syndromic cleft lip and palate; bilateral cleft lip and palate; unilateral cleft lip and palate; lip morphology; nasolabial angle

\section{Introduction}

Artificial intelligence (A.I.) is a fast-growing technology and leading in many areas of our lives. Recently, A.I. built algorithms have been integrated into day-to-day technologies and are being used extensively. Internet search engines, online assistants, or filtering mail spam or speech and even image identification on social media are some of its related applications. Recent scoping reviews focused on the use of A.I. in orthodontics and in cleft lip and/or palate have highlighted the growing interest of the research community in this field [1,2]. Artificial intelligence has been used to detect landmarks of lateral cephalograms [3,4], aid in diagnosis [5,6], and plan treatments for cases. In patients with a cleft lip and/or palate, it has been used for pre-natal diagnosis, researching its etiology, detecting landmarks, and predicting the need for surgery later in life. These systems have used multiple forms of deep learning, such as neural networks, decision trees, random forests, and k-nearest neighbor algorithms to develop A.I. models that can help orthodontists [1,2]. 
Various recent studies have highlighted the high accuracy of landmark identification by algorithms. Kunz et al. (2020) revealed the contribution of A.I. in Orthodontics, where AI built software was able to analyze unknown lateral cephalograms (Late. Ceph.) with almost a comparable level of quality of the gold standard where interpretation is completed manually by a specialist [7]. Lee et al. (2020) utilized similar A.I.-driven deep convolutional neural networks-built evaluations of Late. Ceph. for the indication of Surgical Orthodontic cases' differential diagnoses and found 95.6\% accuracy [8]. The analysis claimed to be the first to effectively enable such applications. Progressions in computing in the recent era, such A.I.-driven tasks, can be used for multifarious duties. Especially in health care, A.I. has shown enormous success in the way to assist clinicians/radiologists/specialists in examining medical X-rays/imaging, to aid in the diagnosis of certain types of diseases, various types of cancer [9], and early revealing of Alzheimer's disease [10]. Thus, A.I.driven systems can support therapeutic decisions. In Orthodontics, perfect landmark identification is required for successful Late. Ceph. analysis for the effective diagnosis and management. The erroneous identification of landmarks in Late. Ceph. might lead to wrong diagnoses for Orthodontic management. A recent artificial intelligence-based system of landmark identification demonstrated an accuracy comparable to experts [11]. Thus, fully computerized and consistent identification based on an A.I.-driven system for the Late. Ceph. landmarks is required [8,12].

The cleft of the lip and/or palate (CLP) is one of the common birth defects of the head and neck origin with a multifarious etiology [13]. CLP can happen as part of wideranging chromosomal abnormalities or in isolation or along with teratogenic syndromes. The etiology of non-syndromic cleft lip and/or palate is attributed to environmental and genetic factors and the interactions among them [14]. CLP patients suffers with multiple dental and craniofacial problems. Altered facial esthetic harmony and maxillary growth retardation are commonly seen in CLP patient $[15,16]$. A recent study noted that the facial profiles of individuals with operated bilateral cleft and/or palate were found to be esthetically unpleasant by orthodontists and surgeons who were not involved in cleft care [17]. The face is the most variable part of the body. Variability of the face manifested by the altered sizes and shapes of subjects features and even more by the associations of these features to each other. It is seen that facial soft tissue characteristics vary with different skeletal relations of the jaws. A previous study has also noted that the perception of facial esthetics is influenced by various biopsychosocial factors [18]. Altered upper lip morphology (LM) especially the naso-labial region appears to exemplify the facial harmony of CLP patients [19]. CLP patients usually undergo lip surgery and palate surgery by the age of 0 to 6 months and 12-18 months, respectively [20]. The defect itself and the multiple surgery might influence the growth retardation around the maxillary region leading LM and NLA disorientation.

Till date, based on literature search, no studies have been conducted in the Saudi population, where different types of non-syndromic cleft lip and/or palate (NSCLP) and non-cleft (NC) subjects have been studied in regard to LM and NLA. The present study is first of its kind where an attempt is made to assess by an A.I.-based analysis of the LM and nasolabial angle (NLA) in different types of NSCLP and with a well-matched control subject without any clefts (NC). The aim of this study was to investigate (1) the variation in the lip morphology among different NSCLP and NC individuals, (2) the variation in the NLA among NSCLP and NC individuals, and (3) the possibility of variation between gender, side of the cleft, and variations among groups.

\section{Materials and Methods}

This retrospective investigation has been officially approved by the Institutional Review Board of Alrass Dental Research Center, Qassim University with the ethical clearance Code \#: DRC/009FA/20. 


\subsection{Sample}

A total of 123 non-orthodontically treated subjects, comprising of 69 male and 54 females, were investigated in this study. Among them, there were 31 healthy Saudi subjects (NC), and 92 subjects were in the category of NSCLP [11,12]. Among 92 NSCLP, subject afflictions included 29 bilateral cleft lip and palate (BCLP), 41 unilateral cleft lip and palate (UCLP), 9 unilateral cleft alveolus (UCLA), and 13 unilateral cleft lip (UCL). The mean [SD] age of the subjects was 13.29 [3.52] (NC), 14.07 [4.73] (BCLP), 14.32 [4.46] (UCLP), 12.78 [4.09] (UCLA), and 13.31 [4.46] (UCL) years, respectively. Twenty-seven subjects had UCLP, UCLA, and UCL affected on their right side, and 36 subjects were affected on their left side. Standardized digital Late. Ceph. for all the above-mentioned subjects were studied. The sample recruited and analyzed for investigation for the current study were based on convenient sampling with pre-decided inclusion and exclusion criteria.

The following inclusion criteria were required for this study [21-23]:

Patient should have no other congenital diseases besides NSCLP.

1. Subjects had undergone their cleft lip and palate surgery during their childhood.

2. No orthodontic treatment has been done for any participants.

3. All clinical records and radiographs (Late. Ceph. and OPG) were taken by a Saudi board-certified dental resident.

4. Late. Ceph. must show all of the landmarks planned to be used in the study.

5. Lips should close smoothly.

6. Bite should be registered in centric occlusion.

The exclusion criteria were as follows:

1. Late. Ceph. that had any artefacts in the area of interest.

2. Radiographs that were of poor quality due to exposure parameters.

3. Radiographs that were blurred due to movement of patients.

\subsection{Measurements}

In the current study, to ensure consistency and reproducibility, the measurements were performed through automated Late. Ceph. analysis using a specialized A.I. algorithm technique [Webceph (Korea)]. A Total of 6 points, 1 plane, 2 linear measurements and 1 angle were measured for analysis of LM morphology [24] (LM-1 and LM-2) and NLA. Each Late. Ceph. traced using automated A.I.-driven software, landmarks and angular measurements were carried out by single specialist examiner. The details of landmarks, angular, and linear measurements used in this study are described in Figure 1 and Table 1.

Table 1. Soft tissue landmarks, angular, and linear measurements.

\begin{tabular}{cc}
\hline Prn (pronasale) & the most prominent point of the nose. \\
\hline Cm (Highest point of columella) & the most anterior and highest part of the columella. \\
\hline Sn (subnasale) & the point at which the columella merges with the upper lip in the midsagittal plane. \\
\hline Ls (labiale superius) & the most anterior point on the upper lip. \\
\hline Li (labiale inferius) & the most anterior point on the soft tissue chin. \\
\hline Pog (soft tissue pogonion) & the acute angle formed by profile points highest point of columella, subnasale, and \\
labiale superius.
\end{tabular}




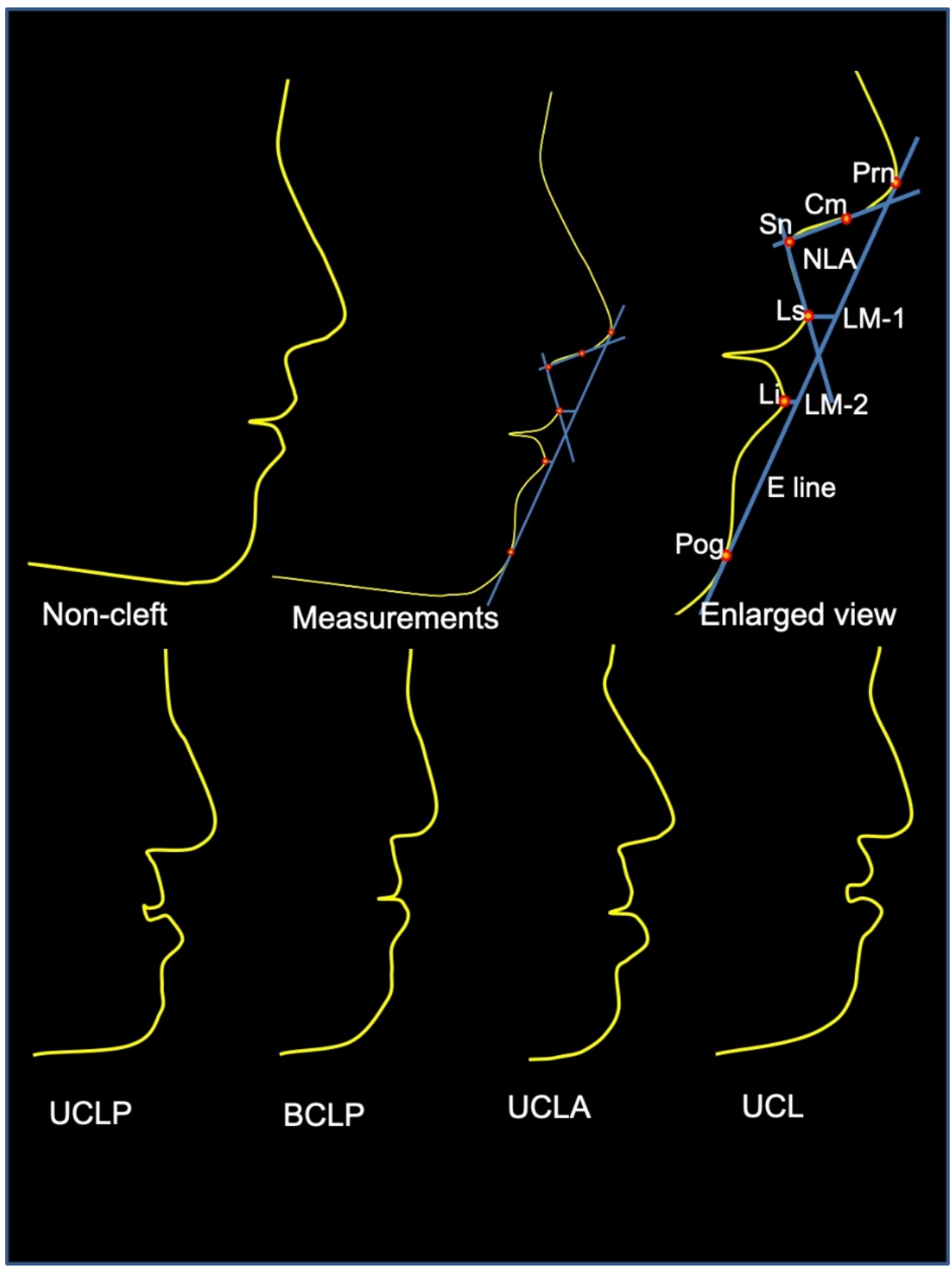

Figure 1. Profile view of non-cleft, unilateral cleft lip and palate (UCLP), bilateral cleft lip and palate (BCLP), unilateral cleft lip and alveolus (UCLA), and unilateral cleft lip (UCL) and soft tissue landmarks, angular, and linear measurements used in this study.

\subsection{Statistical Analyses}

Analyzed data sets are presented in Table 2. Gender and side disparities with respect to LM and NLA were assessed using an independent $t$-test. Comparison among groups was conducted using ANOVA followed by multiple comparison using post-hoc tests. These analyses were carried out using statistical package for social sciences (SPSS Inc., SPSS Ver. 26.0, Chicago, IL, USA). The reliability of the method was analyzed by Dahlberg's formula, $\mathrm{ME}=\sqrt{ } \Sigma\left(\mathrm{x}_{1}-\mathrm{x}_{2}\right) 2 / 2 \mathrm{n}$, to determine the difference between 2 measurements [25]. Twenty randomly selected Late. Ceph. were retraced and re-measured to calculate the method errors. 
Table 2. Measured data for Upper lip to E plane (LM-1), Lower lip to E plane (LM-2) and Nasolabial angle (NLA) of non-cleft, unilateral cleft lip and palate (UCLP), bilateral cleft lip and palate (BCLP), unilateral cleft lip and alveolus (UCLA), and unilateral cleft lip (UCL) $(\mathrm{N}=123$, Non-cleft $=31$, $\mathrm{BCLP}=29, \mathrm{UCLP}=41, \mathrm{UCLA}=9$, and $\mathrm{UCL}=13$ ).

\begin{tabular}{|c|c|c|c|c|c|c|c|c|c|c|c|c|}
\hline \multirow[t]{2}{*}{ SN } & \multicolumn{3}{|c|}{ Non-Cleft } & \multicolumn{3}{|c|}{ BCLP } & \multicolumn{3}{|c|}{ UCLP } & \multicolumn{3}{|c|}{ UCLA } \\
\hline & LM-1 & LM-2 & NLA & LM-1 & LM-2 & NLA & LM-1 & LM-2 & NLA & LM-1 & LM-2 & NLA \\
\hline 1 & 0.52 & 2.09 & 90.21 & -2.74 & -0.12 & 87.77 & -5.83 & 0.61 & 69.68 & 1.17 & 3.64 & 82.28 \\
\hline 2 & -3.04 & -1.57 & 95.12 & -6.71 & 3.20 & 43.10 & -11.49 & -0.09 & 95.43 & -5.70 & 0.97 & 86.80 \\
\hline 3 & -8.21 & -4.75 & 116.33 & -1.74 & 4.34 & 102.57 & -4.57 & -1.36 & 89.20 & 0.19 & 3.83 & 85.17 \\
\hline 4 & 3.00 & 3.53 & 89.54 & -5.83 & -0.54 & 84.63 & -1.87 & 5.22 & 58.79 & -6.74 & 0.87 & 66.45 \\
\hline 5 & -3.80 & -1.60 & 74.36 & -4.90 & 1.55 & 97.38 & -3.45 & 2.49 & 79.37 & 0.21 & 2.93 & 86.38 \\
\hline 6 & -1.96 & 1.56 & 83.91 & -4.88 & 0.80 & 94.13 & -2.11 & 3.55 & 81.77 & 2.86 & 3.11 & 102.06 \\
\hline 7 & 1.54 & 5.54 & 91.30 & -4.49 & 1.01 & 89.37 & -0.60 & 4.58 & 90.35 & -2.03 & 3.05 & 90.88 \\
\hline 8 & 1.35 & 5.62 & 83.00 & -6.71 & 1.59 & 102.79 & -2.89 & 3.30 & 89.00 & -8.31 & 0.70 & 53.00 \\
\hline 9 & 2.30 & 5.79 & 89.04 & -6.97 & 3.14 & 108.71 & -3.20 & 2.65 & 70.24 & -3.44 & 3.62 & 77.47 \\
\hline 10 & -2.42 & -3.01 & 77.24 & -6.00 & -1.43 & 75.69 & -3.42 & 1.49 & 79.04 & & & \\
\hline 11 & 0.13 & 1.10 & 93.49 & -13.68 & 4.97 & 70.79 & -2.92 & 5.11 & 79.36 & & UCL & \\
\hline 12 & -3.67 & -0.75 & 100.03 & -6.39 & 1.53 & 83.85 & -5.92 & -0.91 & 86.72 & & & \\
\hline 13 & -2.87 & -2.23 & 90.58 & -11.87 & 2.91 & 85.81 & -8.57 & -4.04 & 81.10 & -6.34 & 1.93 & 80.57 \\
\hline 14 & -0.63 & -0.04 & 94.99 & -8.53 & -1.61 & 80.94 & -2.99 & 4.86 & 80.61 & -2.47 & 0.73 & 83.13 \\
\hline 15 & 3.48 & 5.11 & 90.69 & 0.42 & 8.04 & 87.55 & -11.28 & -0.58 & 75.13 & -3.15 & 0.43 & 91.10 \\
\hline 16 & 1.76 & 5.46 & 78.34 & -5.41 & -0.33 & 80.91 & -2.91 & 1.40 & 56.34 & 1.75 & 2.41 & 85.56 \\
\hline 17 & -4.81 & -3.68 & 87.10 & -14.88 & -6.49 & 66.24 & -6.07 & 2.78 & 82.52 & 4.93 & 9.12 & 94.25 \\
\hline 18 & 2.74 & 6.42 & 103.18 & -4.47 & -1.55 & 73.86 & -4.61 & 2.30 & 51.65 & -0.97 & 3.99 & 68.11 \\
\hline 19 & -5.15 & -0.53 & 80.02 & -4.85 & 1.30 & 95.22 & -8.25 & 1.10 & 86.54 & -3.07 & 5.40 & 72.82 \\
\hline 20 & -3.34 & -0.47 & 117.40 & -3.87 & 4.84 & 61.53 & -7.29 & -0.42 & 78.20 & 0.39 & 3.40 & 82.28 \\
\hline 21 & -5.19 & -1.79 & 89.61 & -4.64 & 2.29 & 89.29 & -7.63 & -0.70 & 88.34 & -6.21 & -0.52 & 123.10 \\
\hline 22 & -4.14 & -5.32 & 138.23 & -1.43 & -0.70 & 96.05 & -12.36 & -4.65 & 88.54 & -4.52 & -0.85 & 86.24 \\
\hline 23 & -2.23 & -1.34 & 99.96 & -14.01 & 3.36 & 87.27 & -10.89 & -1.44 & 109.05 & -1.33 & 4.00 & 67.87 \\
\hline 24 & -3.77 & -2.00 & 106.37 & -11.01 & -0.72 & 71.34 & -11.11 & -3.01 & 61.64 & -11.85 & -1.90 & 44.72 \\
\hline 25 & -2.55 & -1.05 & 126.48 & -10.18 & -1.01 & 95.55 & -15.03 & -3.20 & 87.27 & 3.48 & 7.69 & 92.95 \\
\hline 26 & -4.99 & 0.53 & 133.19 & -4.52 & 3.80 & 76.53 & -9.79 & -1.83 & 77.84 & & & \\
\hline 27 & -1.78 & -3.71 & 116.57 & -2.65 & 1.80 & 71.15 & -12.63 & -6.13 & 84.47 & & & \\
\hline 28 & 2.91 & 6.16 & 93.82 & -11.26 & -0.58 & 90.24 & -4.19 & 2.00 & 78.32 & & & \\
\hline 29 & -3.10 & -3.07 & 101.43 & -16.82 & -6.89 & 100.01 & -3.47 & 1.44 & 89.50 & & & \\
\hline 30 & -0.75 & 0.52 & 83.12 & & & & -3.05 & 3.53 & 72.21 & & & \\
\hline 31 & 0.31 & 2.61 & 98.54 & & & & 0.58 & 3.64 & 66.85 & & & \\
\hline 32 & & & & & & & -5.62 & 3.40 & 91.36 & & & \\
\hline 33 & & & & & & & -6.98 & 0.89 & 77.51 & & & \\
\hline 34 & & & & & & & -6.27 & 1.04 & 69.71 & & & \\
\hline 35 & & & & & & & -16.18 & -11.76 & 103.45 & & & \\
\hline 36 & & & & & & & -5.10 & 2.74 & 78.32 & & & \\
\hline 37 & & & & & & & -16.86 & -6.93 & 99.97 & & & \\
\hline 38 & & & & & & & -4.45 & 0.48 & 70.93 & & & \\
\hline 39 & & & & & & & -9.37 & 2.30 & 76.10 & & & \\
\hline 40 & & & & & & & -6.62 & 0.69 & 75.34 & & & \\
\hline 41 & & & & & & & -3.01 & 1.84 & 67.85 & & & \\
\hline
\end{tabular}

\section{Results}

The mean Error for LM-1 and LM 2 was about $0.299 \mathrm{~mm}$ and $2.8^{\circ}$ for NLA, which is considered acceptable. 


\subsection{LM/Esthetic Plane Analysis}

The LM study of Ricketts [24] is built on the esthetic plane, which is a line drawn tangent to the tip of the nose and soft tissue pogonion [24] (Figure 1). A profile is studied to be preferably beautiful when the LM-2 is approximately $2.0 \mathrm{~mm}$, and the LM-1 is about $4.0 \mathrm{~mm}$ posterior to the esthetic plane [13]. In this study, LM was posterior to the esthetic plane in $64.52 \%$ (NC), $96.55 \%$ (BCLP), $97.56 \%$ (UCLP), $55.56 \%$ (UCLA), and $69.23 \%$ (UCL) with respect to LM-1, whereas $54.84 \%$ (NC), 41.38\% (BCLP), 36.59\% (UCLP), 0\% (UCLA), and $23.08 \%$ (BCLP) were recorded for the LM-2. The LM touching and anterior to the esthetic plane were $6.45 \%$ and $29.03 \%$ (NC), 3.45\% and $0 \%$ (BCLP), $0 \%$ and $2.44 \%$ (UCLP), $22.22 \%$ and $22.22 \%$ (UCLA), and $7.69 \%$ and $23.08 \%$ (UCL) for the LM-1, and $0 \%$ and $45.16 \%$ (NC), $0 \%$ and $58.62 \%$ (BCLP), $2.44 \%$ and $60.98 \%$ (UCLP), $0 \%$ and $100 \%$ (UCLA), and $7.69 \%$ and $69.23 \%$ (UCL) for the LM-2, respectively (Table 2). Ricketts norms for LM-1 and LM-2 (LM-1/LM-2, $-4 \mathrm{~mm} /-2 \mathrm{~mm}$ ) were the closest to the values, and we did not find any for the groups (LM-1/LM-2, -1.56 (NC), -6.93 (BCLP), -6.59 (UCLP), -2.42 (UCLA), and -2.26 (UCL) mm/0.49 (NC), 0.98 (BCLP), 0.45 (UCLP), 2.52 (UCLA), and 2.76 (UCL) mm). In relation to LM-1, significant disparities were found among groups. No significant gender and side disparities (Tables 3 and 4) and among all groups were found in relation to LM-2 (Figure 2).

Table 3. Gender disparities for Upper lip to E plane (LM-1), Lower lip to E plane (LM-2), and Nasolabial angle (NLA) among non-cleft and cleft individuals.

\begin{tabular}{|c|c|c|c|c|c|c|c|}
\hline \multirow[t]{2}{*}{ Grouping } & \multirow[t]{2}{*}{ Variables } & \multirow[t]{2}{*}{ Gender } & \multirow[t]{2}{*}{ Mean } & \multirow[t]{2}{*}{ SD } & \multicolumn{2}{|c|}{$95 \%$ CI } & \multirow[t]{2}{*}{$p$-Value } \\
\hline & & & & & Lower & Upper & \\
\hline \multirow[t]{6}{*}{ Non-cleft } & LM-1 & $\mathrm{M}$ & -1.355 & 2.366 & -1.859 & 2.606 & 0.734 \\
\hline & & $\mathrm{F}$ & -1.729 & 3.469 & & & \\
\hline & LM-2 & M & 0.648 & 3.434 & -2.340 & 2.923 & 0.822 \\
\hline & & $\mathrm{F}$ & 0.357 & 3.668 & & & \\
\hline & NLA & $\mathrm{M}$ & 100.752 & 20.096 & -5.357 & 18.313 & 0.272 \\
\hline & & F & 94.274 & 11.739 & & & \\
\hline \multirow[t]{6}{*}{ BCLP } & LM-1 & $\mathrm{M}$ & -6.533 & 4.513 & -2.277 & 5.165 & 0.433 \\
\hline & & $\mathrm{F}$ & -7.978 & 3.913 & & & \\
\hline & LM-2 & M & 0.780 & 3.540 & -3.447 & 1.977 & 0.583 \\
\hline & & $\mathrm{F}$ & 1.515 & 1.799 & & & \\
\hline & NLA & M & 87.195 & 12.135 & -1.876 & 21.474 & 0.096 \\
\hline & & F & 77.396 & 17.400 & & & \\
\hline \multirow[t]{6}{*}{ UCLP } & LM-1 & $M$ & -6.785 & 4.749 & -3.113 & 2.321 & 0.770 \\
\hline & & $\mathrm{F}$ & -6.389 & 3.768 & & & \\
\hline & LM-2 & M & 0.190 & 4.005 & -2.780 & 1.721 & 0.637 \\
\hline & & $\mathrm{F}$ & 0.720 & 3.026 & & & \\
\hline & NLA & $\mathrm{M}$ & 81.572 & 9.908 & -4.211 & 11.095 & 0.369 \\
\hline & & $\mathrm{F}$ & 78.130 & 14.060 & & & \\
\hline \multirow[t]{6}{*}{ UCLA } & LM-1 & $\mathrm{M}$ & -1.943 & 3.916 & -5.364 & 8.231 & 0.633 \\
\hline & & $\mathrm{F}$ & -3.377 & 4.417 & & & \\
\hline & LM-2 & $\mathrm{M}$ & 2.673 & 1.379 & -1.833 & 2.727 & 0.657 \\
\hline & & $\mathrm{F}$ & 2.227 & 1.323 & & & \\
\hline & NLA & M & 83.372 & 11.718 & -18.207 & 31.443 & 0.548 \\
\hline & & $\mathrm{F}$ & 76.753 & 20.694 & & & \\
\hline \multirow[t]{6}{*}{ UCL } & LM-1 & $\mathrm{M}$ & -1.917 & 5.005 & -4.972 & 6.451 & 0.781 \\
\hline & & $\mathrm{F}$ & -2.657 & 4.219 & & & \\
\hline & LM-2 & M & 3.060 & 3.158 & -3.546 & 4.862 & 0.737 \\
\hline & & $\mathrm{F}$ & 2.402 & 3.737 & & & \\
\hline & NLA & M & 76.791 & 16.796 & -34.064 & 9.260 & 0.234 \\
\hline & & $\mathrm{F}$ & 89.193 & 18.707 & & & \\
\hline
\end{tabular}


Table 4. Side disparities for Upper lip to E plane (LM-1), Lower lip to E plane (LM-2), and Nasolabial angle (NLA) among non-cleft, unilateral cleft lip and palate (UCLP), unilateral cleft lip and alveolus (UCLA), and unilateral cleft lip (UCL) individuals $(\mathrm{N}=63$, Right $=27$, and Left $=36$ ).

\begin{tabular}{ccccccc}
\hline Variables & Side & Mean & SD & \multicolumn{2}{c}{$95 \%$ CI } & $p$-Value \\
& & & & Lower & Upper & \\
\hline \multirow{2}{*}{ LM-1 } & Right & -5.208 & 4.706 & -2.575 & 2.203 & 0.877 \\
& Left & -5.022 & 4.683 & & & \\
LM-2 & Right & 0.480 & 3.734 & -3.005 & 0.410 & 0.134 \\
& Left & 1.777 & 3.043 & & & \\
NLA & Right & 82.949 & 13.428 & -2.823 & 10.988 & 0.242 \\
& Left & 78.866 & 13.665 & & & \\
\hline
\end{tabular}
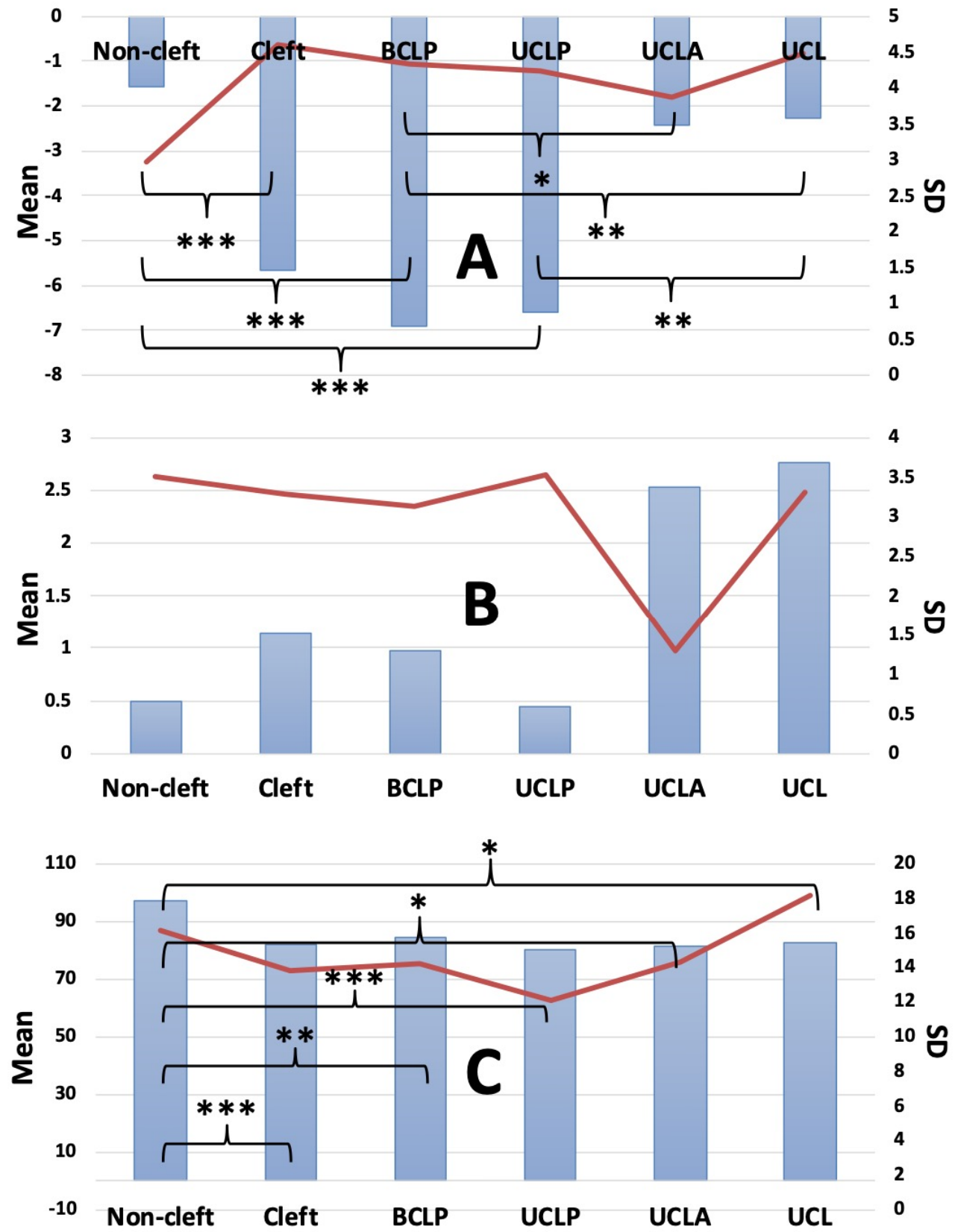

Figure 2. Multiple group comparison results of Upper lip to E plane (LM-1) (A), Lower lip to E plane (LM-2) (B), and Nasolabial angle (NLA) (C) in non-cleft, unilateral cleft lip and palate (UCLP), bilateral cleft lip and palate (BCLP), unilateral cleft lip and alveolus (UCLA), and unilateral cleft lip (UCL) individuals. $\left(p<0.05=^{*}, p<0.01=^{* *}, p<0.001=^{* * *}\right)$. 


\subsection{Nasolabial Angle Analysis (NLA)}

1. The NLA angle formed from the columella, subnasale, and labiale superius of the subjects were 97.199 (NC), 84.492 (BCLP), 79.893 (UCLP), 81.166 (UCLA), and 82.515 (UCL), respectively (Figure 2 ).

2. Compared to NC and all 4 cleft groups, NLA showed significant disparities. Among NSCLP no significant disparities were found.

3. No significant gender disparities among all groups were found (Table 3).

4. No significant side disparities were found (Table 4).

\section{Discussion}

With the latest advancement in the Orthodontic tools, attempts have been made to introduce A.I.-driven image recognition technology in the medical/dental image field [7,8,12]. In Orthodontics, despite the variety of techniques, to utilize digital image recognition and image processing technology especially for the Late. Ceph. analysis, in the present study, A.I.-driven automated Late. Ceph. analysis has been used, which is a novel technique and claimed to be the future of digital Orthodontics. This method was able to detect Late. Ceph. anatomical landmarks within a clinically suitable range and comparable with the human-measured gold standard protocol [7,8,12]. A.I.-driven automated detection of landmarks and Late. Ceph. analysis showed acceptable success rates compared to the most commonly used digital techniques [12].

CLP alters facial soft tissues in mostly the oro-nasal area, resulting in the deviation and alteration of nose and upper lip. Thus, we ascertained deviations of LM-1 and NLA leading esthetically unacceptable facial soft tissue morphology [25]. Multiple dental anomalies, alteration in occlusion, and maxillary growth retardation are also common features in CLP. However, among different types of NSCLP, these alterations vary case by case $[15,26]$. Celikoglu et al. [27] found that the BCLP group revealed larger vertical growth, larger retrusion of the maxilla and the maxillary and mandibular incisors, and decreased subnasale and labrale superior thicknesses compared with the well-matched controls (NC). These dissimilarities should be taken into account when planning Orthodontic and Orthognathic Surgery treatment for such patients.

Measurement of the lips in relation to the Ricketts E-line [24] focuses on the relationship of nose, lips, and chin. Studying variations in soft tissue profile after Orthodontic management with and without extractions of 80 turkey patients with angle Class I malocclusion, Kocadereli, [28] suggested that the mean values for LM-1 and LM-2 were slightly more protrusive than the Ricketts esthetic ideal. Satravaha and Schlegel [29] revealed that $30 \%$ and $45 \%$ of the Thai population and the Thai population of Chinese origin, respectively, are found to have protrusive lips. Alcalde et al. [30] revealed that the LM-1 and LM-2 of the Japanese were anteriorly positioned in all analyses. Our result suggests that most of the Saudis' [NC and NSCLP] lip positions were posterior to the esthetic plane, which is "ideal" in accordance with the Ricketts findings [24].

In the present study NLA showed large variability, at $97.199 \pm 16.10(\mathrm{NC}), 84.492 \pm 14.17$ (BCLP), $79.893 \pm 12.08$ (UCLP), $81.166 \pm 14.28$ (UCLA), and $82.515 \pm 18.12$ (UCL), respectively. Paradowska-Stolarz and Kawala [31] studied NLA on Poland NC and CLP subjects. They found that in any cleft group the variability was $100.36 \pm 18.13$ for boys and $101.14 \pm 17.51$ for girls, in CLP-R 94.48 \pm 17.11 for boys and $98.17 \pm 10.72$ for girls, in CLP-L $100.11 \pm 14.98$ for boys and $100.81 \pm 19.52$ for girls, in BCLP $108.83 \pm 23.94$ for boys and $103.38 \pm 16.20$ for girls, and in NC $116.60 \pm 11.53$ for boys and $112.77 \pm 13.17$ for girls. Rhee et al. [32] found NLA in female NC subjects 103.43 degrees in Korean, 99.87 degrees in Japanese, 113.51 degrees in Chinese, and 106.52 degrees in Western subjects. Almoammar et al. [33] studied 96 NSUCCLP subjects in two groups, 33 and 63 subjects without missing teeth and missing teeth with NLA $107.78 \pm 12.76$ and $107.3 \pm 11.46$, respectively. Oh et al. [34] found that the NLA of American and Chinese patients were $127.3 \pm 8.2$ and $97.1 \pm$ 9.6. These disparities in NLA are claimed due to more prominent noses of American patients than Chinese patients. Russell et al. [35] explains that the reason behind these 
disparities are due to the base of the nose of CLP patients intruding on the upper lip, and thus it shows down-turned. Hence, the NLA of CLP patients is smaller than that of the overall population, which is in agreement with the present study results. Additionally, Caucasians' noses are more pointed, and Asians' noses are flatter; thus the NLA of Asians is smaller compared to Caucasians. As observed, values of the NLA quite vary with the previously reported articles; therefore, the results of this measurement should be interpreted with caution.

We used the data of five different groups of subjects. To the best of our knowledge, A.I.-driven automated Late. Ceph. analysis in such groups and population is yet to be investigated. Negligible error in the measurements; precise, automated, simple, quick, cost-effective, future Orthodontic digital tools; and multiple groups of special samples are the novelty of the current study. The current study outcomes may help clinicians in approaches where the influences of primary lip and palate surgeries are on LM and NLA, aiding in the rehabilitation process of subjects with different types of NSCLP in developing a favorable management protocol.

The limitation of our study was the small sample size of the study groups, being for especially UCLA and UCL. Following strict inclusion criteria, a good number of BCLP and UCLP samples and age-sex matched control group were recruited. We cannot draw any strong conclusion, as the influences of multiple surgery are not investigated. Further, genetic/congenital and postnatal treatment factors might alter growth or shape of the segments, thus causing additional biases of the influences of a wide range of such factors. Future studies involving effects of postnatal treatment factors along with larger numbers of subjects is recommended.

\section{Conclusions}

The results revealed here imply that despite the primary surgical repair of the lip and palate, the patients with different types of NSCLP still show variable degrees of dysmorphology in LM and NLA in comparison to NC subjects. Furthermore, the study demonstrated that the A.I.-driven automated Late. Ceph. analysis system is a suitable, simple and a time-efficient approach. Its application in the clinical setting includes the identification of Late.Ceph. landmark, linear, and angular analysis.

Author Contributions: Conceptualization, M.K.A., A.A.A., F.A., H.J.A. and P.K.C.; methodology, M.K.A. and A.A.A.; software, M.K.A. and A.A.A.; validation, M.K.A. and A.A.A.; formal analysis, M.K.A. and A.A.A.; investigation, M.K.A. and A.A.A.; resources, M.K.A., A.A.A., F.A., H.J.A. and P.K.C.; data curation, M.K.A. and A.A.A.; writing-original draft preparation, M.K.A. and A.A.A.; writing-review and editing, M.K.A., A.A.A., F.A., H.J.A. and P.K.C.; funding acquisition, M.K.A. All authors have read and agreed to the published version of the manuscript.

Funding: The authors extend their appreciation to the Deanship of Scientific Research at Jouf University for funding this work through research grant no. (DSR-2021-01-0382).

Institutional Review Board Statement: All the data (medical records and X-rays) of this study were collected from the Saudi Board of Dental Residents and approved by the Ethical Committee of Al Rass Dental Research Center, Qassim University (DRC/009FA/20), which complies with the Declaration of Helsinki. Strengthening the Reporting of Observational Studies in Epidemiology (STROBE) guidelines are followed to design and conduct the study.

Informed Consent Statement: Written, informed consent was obtained from all the subjects (one of the parents, either father and/or mother or legal guardian, for adolescent subjects).

Data Availability Statement: The data used to support the findings of this study are included in the article.

Acknowledgments: The authors would like to thank the Dean of Scientific Research at Jouf University for funding this work.

Conflicts of Interest: The authors declare no conflict of interest. 


\section{References}

1. Mohammad-Rahimi, H.; Nadimi, M.; Rohban, M.H.; Shamsoddin, E.; Lee, V.Y.; Motamedian, S.R. Machine Learning and Orthodontics, Current Trends and the Future Opportunities: A Scoping Review. Am. J. Orthod. Dentofac. Orthop. 2021, 160, 170-192.e4. [CrossRef]

2. Chaudhari, P.K.; Alam, M.K. Current Applications of Artificial Intelligence in Cleft Care: A Scoping Review. Front. Med. 2021, 8,14 .

3. Oh, K.; Oh, I.-S.; Le, V.N.T.; Lee, D.-W. Deep Anatomical Context Feature Learning for Cephalometric Landmark Detection. IEEE J. Biomed. Health Inform. 2021, 25, 806-817. [CrossRef] [PubMed]

4. Song, Y.; Qiao, X.; Iwamoto, Y.; Chen, Y. Automatic Cephalometric Landmark Detection on X-Ray Images Using a Deep-Learning Method. Appl. Sci. 2020, 10, 2547. [CrossRef]

5. Amasya, H.; Yildirim, D.; Aydogan, T.; Kemaloglu, N.; Orhan, K. Cervical Vertebral Maturation Assessment on Lateral Cephalometric Radiographs Using Artificial Intelligence: Comparison of Machine Learning Classifier Models. Dentomaxillofac. Radiol. 2020, 49, 20190441. [CrossRef]

6. Yu, H.J.; Cho, S.R.; Kim, M.J.; Kim, W.H.; Kim, J.W.; Choi, J. Automated Skeletal Classification with Lateral Cephalometry Based on Artificial Intelligence. J. Dent. Res. 2020, 99, 249-256. [CrossRef]

7. Kunz, F.; Stellzig-Eisenhauer, A.; Zeman, F.; Boldt, J. Artificial Intelligence in Orthodontics: Evaluation of a Fully Automated Cephalometric Analysis Using a Customized Convolutional Neural Network. J. Orofac. Orthop. 2020, 81, 52-68. [CrossRef]

8. Lee, K.-S.; Ryu, J.-J.; Jang, H.S.; Lee, D.-Y.; Jung, S.-K. Deep Convolutional Neural Networks Based Analysis of Cephalometric Radiographs for Differential Diagnosis of Orthognathic Surgery Indications. Appl. Sci. 2020, 10, 2124. [CrossRef]

9. Vial, A.; Stirling, D.; Field, M.; Ros, M.; Ritz, C.; Carolan, M.; Holloway, L.; Miller, A.A. The Role of Deep Learning and Radiomic Feature Extraction in Cancer-Specific Predictive Modelling: A Review. Transl. Cancer Res. 2018, 7, 803-816. [CrossRef]

10. Ding, Y.; Sohn, J.H.; Kawczynski, M.G.; Trivedi, H.; Harnish, R.; Jenkins, N.W.; Lituiev, D.; Copeland, T.P.; Aboian, M.S.; Mari Aparici, C. A Deep Learning Model to Predict a Diagnosis of Alzheimer Disease by Using 18F-FDG PET of the Brain. Radiology 2019, 290, 456-464. [CrossRef]

11. Kim, H.; Shim, E.; Park, J.; Kim, Y.-J.; Lee, U.; Kim, Y. Web-Based Fully Automated Cephalometric Analysis by Deep Learning. Comput. Methods Programs Biomed. 2020, 194, 105513. [CrossRef]

12. Arık, S.Ö.; Ibragimov, B.; Xing, L. Fully Automated Quantitative Cephalometry Using Convolutional Neural Networks. J. Med. Imaging 2017, 4, 014501. [CrossRef]

13. Tolarova, M.M. Global Health Issues Related to Cleft Lip and Palate: Prevention and Treatment Need to Team Together. Indian J. Dent. Res. 2016, 27, 455. [CrossRef]

14. Mossey, P.A.; Little, J.; Munger, R.G.; Dixon, M.J.; Shaw, W.C. Cleft Lip and Palate. Lancet 2009, 374, 1773-1785. [CrossRef]

15. Alam, M.K.; Iida, J.; Sato, Y.; Kajii, T.S. Postnatal Treatment Factors Affecting Craniofacial Morphology of Unilateral Cleft Lip and Palate (UCLP) Patients in a Japanese Population. Br. J. Oral. Maxillofac. Surg. 2013, 51, e205-e210. [CrossRef] [PubMed]

16. Haque, S.; Alam, M.K. Common Dental Anomalies in Cleft Lip and Palate Patients. Malays. J. Med. Sci. 2015, 22, 55-60.

17. De Lauris, R.C.M.C.; Capelozza, L.; Calil, L.R.; Lauris, J.R.P.; Janson, G.; Garib, D.G. Facial Profile Esthetics in Operated Children with Bilateral Cleft Lip and Palate. Dent. Press J. Orthod. 2017, 22, 41-46. [CrossRef] [PubMed]

18. Tole, N.; Lajnert, V.; Kovacevic Pavicic, D.; Spalj, S. Gender, Age, and Psychosocial Context of the Perception of Facial Esthetics. J. Esthet. Restor. Dent. 2014, 26, 119-130. [CrossRef]

19. Phillips, G.S.A.; Swan, M.C.; Sawyer, A.R.; Goodacre, T.E.E.; Cadier, M. A Comparative Study of the Aesthetic Outcome of Two Techniques for Unilateral Complete Cleft Lip Repair. Plast. Reconstr. Surg. 2017, 140, 757-764. [CrossRef]

20. Nahai, F.R.; Williams, J.K.; Burstein, F.D.; Martin, J.; Thomas, J. The Management of Cleft Lip and Palate: Pathways for Treatment and Longitudinal Assessment. Semin. Plast. Surg. 2005, 19, 275-285. [CrossRef]

21. Alam, M.K.; Alfawzan, A.A. Evaluation of Sella Turcica Bridging and Morphology in Different Types of Cleft Patients. Front. Cell Dev. Biol. 2020, 8, 656. [CrossRef]

22. Alam, M.K.; Alfawzan, A.A. Dental Characteristics of Different Types of Cleft and Non-Cleft Individuals. Front. Cell Dev. Biol. 2020, 8, 789. [CrossRef]

23. Alam, M.K.; Alfawzan, A.A.; Haque, S.; Mok, P.L.; Marya, A.; Venugopal, A.; Jamayet, N.B.; Siddiqui, A.A. Sagittal Jaw Relationship of Different Types of Cleft and Non-Cleft Individuals. Front. Pediatr. 2021, 9, 651951. [CrossRef]

24. Ricketts, R.M. Esthetics, Environment, and the Law of Lip Relation. Am. J. Orthod 1968, 54, 272-289. [CrossRef]

25. Armijo, B.S.; Brown, M.; Guyuron, B. Defining the ideal nasolabial angle. Plast. Reconstr. Surg. 2012, 129, 759-764. [CrossRef] [PubMed]

26. Smahel, Z.; Polivková, H.; Skvarilová, B.; Horák, I. Configuration of Facial Profile in Adults with Cleft Lip with or without Cleft Palate. Acta Chir. Plast. 1992, 34, 190-203. [PubMed]

27. Celikoglu, M.; Buyuk, S.K.; Sekerci, A.E.; Ersoz, M.; Celik, S.; Sisman, Y. Facial Soft-Tissue Thickness in Patients Affected by Bilateral Cleft Lip and Palate: A Retrospective Cone-Beam Computed Tomography Study. Am. J. Orthod. Dentofac. Orthop. 2014, 146, 573-578. [CrossRef] [PubMed]

28. Kocadereli, I. Changes in Soft Tissue Profile after Orthodontic Treatment with and without Extractions. Am. J. Orthod. Dentofac. Orthop. 2002, 122, 67-72. [CrossRef] 
29. Satravaha, S.; Schlegel, K.D. The Significance of the Integumentary Profile. Am. J. Orthod. Dentofac. Orthop. 1987, 92, 422-426. [CrossRef]

30. Alcalde, R.E.; Jinno, T.; Orsini, M.G.; Sasaki, A.; Sugiyama, R.M.; Matsumura, T. Soft Tissue Cephalometric Norms in Japanese Adults. Am. J. Orthod. Dentofac. Orthop. 2000, 118, 84-89. [CrossRef]

31. Paradowska-Stolarz, A.M.; Kawala, B. The Nasolabial Angle Among Patients with Total Cleft Lip and Palate. Adv. Clin. Exp. Med. 2015, 24, 481-485. [CrossRef]

32. Rhee, S.C.; Kang, S.R.; Park, H.S. Balanced Angular Profile Analysis. Plast. Reconstr. Surg. 2004, 114, 535-544. [CrossRef] [PubMed]

33. Almoammar, K.A.; Almarhoon, H.A.; Batwa, W.; Alqahtani, N.; Al-Jewair, T.; Albarakati, S. Cephalometric Soft Tissue Characteristics of Unilateral Cleft Lip and Palate Patients in Relation to Missing Teeth. BioMed Res. Int. 2017, 2017, 2392808. [CrossRef]

34. Oh, H.S.; Korn, E.L.; Zhang, X.; Liu, Y.; Xu, T.; Boyd, R.; Baumrind, S. Correlations between Cephalometric and Photographic Measurements of Facial Attractiveness in Chinese and US Patients after Orthodontic Treatment. Am. J. Orthod. Dentofac. Orthop. 2009, 136, 762-763. [CrossRef]

35. Russell, K.A.; Orthod, D.; Tompson, B.; Orthod, D.; Paedo, D. Correlation between Facial Morphology and Esthetics in Patients with Repaired Complete Unilateral Cleft Lip and Palate. Cleft Palate Craniofac. J. 2009, 46, 319-325. [CrossRef] [PubMed] 